\title{
Influence of oil droplet size on the oxidative stability of the free and encapsulated fractions of freeze-dried microencapsulated sunflower oil
}

Francisca Holgado, ${ }^{1}$ Gloria Márquez-Ruiz, ${ }^{1}$ M. Victoria Ruiz-Méndez, ${ }^{2}$ and Joaquín Velasco ${ }^{2, *}$

${ }^{1}$ Instituto de Ciencia y Tecnología de Alimentos y Nutrición, Consejo Superior de Investigaciones Científicas (CSIC), c/ José Antonio Novais, 10, E-28040 Madrid, Spain

${ }^{2}$ Instituto de la Grasa, Consejo Superior de Investigaciones Cientificas (CSIC), Campus Universidad Pablo de Olavide, Ctra. de Utrera km 1, E-41013 Sevilla, Spain

*To whom correspondence should be addressed:

Telephone: $\quad+34954611550$

Fax: $\quad+34954616790$

E-mail: jvelasco@ig.csic.es 


\section{Summary}

The effect of oil droplet size (ODS) on the oxidative stability (OS) of dried microencapsulated oils has been scarcely studied and results are contradictory. A few studies have shown increased OS when the ODS was reduced and this was attributed to a decrease in the surface oil content (SOC). Yet, in such studies only the total oil fraction was evaluated. In the present work, the free (FO) and encapsulated oil (EO) fractions of freeze-dried microencapsulated sunflower oil were analysed to study the effect of changes in the ODS by using different homogenisation pressure $(15$ or $70 \mathrm{MPa})$ in the emulsification step. The OS of both the free and encapsulated fractions increased when the ODS was significantly reduced in two samples with different encapsulation matrix, namely, caseinate/lactose and maltodextrin/sucrose/gelatine. A reduction in the SOC would explain the increased stability of the FO, but not that of the EO. An additional protective role of the interfacial film could have been involved. In conclusion, if the encapsulation matrix and the interfacial region are effective as oxygen barriers, a reduction of the ODS of the parent emulsion by an increase in the homogenisation pressure will result in capsules more stable against lipid oxidation.

\section{Keywords}

Oil microencapsulation, high-pressure homogenisation, oil droplet size, freeze-drying, lipid oxidation. 


\section{Introduction}

Oil microencapsulation is mainly aimed at protecting oils from lipid oxidation. Basically, the process consists of two steps. First, the oil is emulsified in an aqueous phase containing complex carbohydrates or a combination of proteins and carbohydrates. Then, the emulsion is dried, normally by spray-drying, to obtain a powder product where the oil in small droplets is entrapped in the inner of solid particles (Ghnimi et al., 2017; Ruiz-Ruiz et al., 2017). Although spray-drying is the drying method normally used in the industry because of its relatively low cost, freeze-drying is one of the methods more recommended for oils highly susceptible to oxidation because it is performed at low temperature and vacuum conditions (Bakry et al, 2016).

The non-encapsulated or free oil fraction, mainly located on the particle surface (Drusch \& Berg, 2008), is theoretically more susceptible to lipid oxidation than the encapsulated fraction because it is more exposed to oxygen. Therefore, the higher the microencapsulation efficiency (ME), the greater will be the oxidative stability. It is widely accepted that ME is influenced by the oil droplet size because the smaller and more uniform the droplets, the greater amount of oil will be covered and entrapped by the encapsulation matrix. Large droplets poorly stabilized tend to form part of the free oil (Drusch \& Berg, 2008; Anwar \& Kunz, 2011). In fact, smaller and more monodisperse emulsions have shown higher ME (Hogan et al., 2001; Keogh et al., 2001; Soottitantawat et al., 2003; 2005; Rusli et al., 2006; Jafari et al., 2008; Holgado et al., 2013; Ramakrishnan et al., 2014).

Studies dealing with the effect of oil droplet size on the oxidative stability of dried microencapsulated oils (DMOs) are however scarce and confusing. According to Shiga et al. (2017) there are no clear reports on the effect of oil droplet size on the oxidative stability of DMO. While a few studies have shown increased oxidative stability when the oil droplet size was reduced (Ishido et al., 2002; Minemoto et al., 2002; Nakazawa et al., 2008; 
Ramakrishnan et al., 2014; Abd Ghani et al., 2016; Shiga et al., 2017), in other studies an increase in ME as a result of decreasing the oil droplet size did not produce longer shelf-life (Risch \& Reineccius, 1988) or even parent emulsions containing larger oil droplets provided DMOs with longer shelf-life (Soottitantawat et al., 2005; Ixtaina et al., 2015). The enhancement in the oxidative stability when the oil droplet size was reduced has been attributed to a decrease in the surface oil content. In contrast, a high proportion of free oil does not necessarily result in low oxidative stability (Drusch et al., 2007). According to Drusch and Berg (2008), the extractable or free oil fraction cannot be used to predict the shelf-life of microencapsulated oils.

In all these studies only the total oil fraction was analysed to evaluate DMO oxidation, mainly due to the low amount of the free oil fraction. Previous studies carried out in our lab have however demonstrated the importance of evaluating both fractions separately. In this regard, separate evaluation of the free and encapsulated oil fractions enabled to elucidate why rancidity was detected when the levels of oxidation compounds were globally very low (Márquez-Ruiz et al., 2003), to get to know that these two fractions had different oxidative patterns (Velasco et al., 2006), that relative humidity mainly affected the oxidative stability of the free oil (Velasco et al., 2009a) and that oxidation of the free oil was responsible for the response of the Rancimat test when this was applied directly to DMOs (Velasco et al., 2009b).

The aim of this work was to study the influence of the oil droplet size on the oxidative stability of DMOs by applying an analytical approach that differs from most of the oxidation studies in these products. In this regard, lipid oxidation was evaluated in the free and encapsulated oil fractions separately rather than in the total oil fraction. Towards this end, freeze-drying was the drying method chosen instead of spray-drying because freeze-dried capsules normally contain relatively greater amount of free oil. To produce DMOs with 
different oil droplet size, different homogenisation pressures (15 or $70 \mathrm{MPa}$ ) were applied in the emulsification step. Two DMO samples containing caseinate/lactose or maltodextrin/sucrose/gelatine were studied. Both matrices were used in a previous physicochemical characterisation study and were chosen due to their relatively high powder physical stability (Holgado et al., 2013).

\section{Materials and methods}

\section{Materials}

Refined conventional sunflower oil was used as a study model and purchased from a local supermarket. Sodium caseinate, D-lactose monohydrate, gelatine from bovine skin and sucrose (99\%) were acquired from Sigma Chemical Co. (St. Louis, MO). Maltodextrin 10 (dextrose equivalent of 10) was purchased from Fluka (Sigma-Aldrich Chemie Steinheim, Germany). All other chemicals used were of analytical grade.

\section{Dried microencapsulated oil samples}

The samples were prepared in triplicate by freeze-drying of $\mathrm{o} / \mathrm{w}$ emulsions. The sample containing sodium caseinate (CAS sample) was made from an emulsion constituted by $10 \%$ sunflower oil, $10 \%$ sodium caseinate and $10 \%$ lactose $(\mathrm{w} / \mathrm{w})$. The one containing maltodextrin (MD sample) was obtained from an emulsion that comprised 10\% sunflower oil, 12\% sucrose, $7 \%$ maltodextrin (DE 10) and 1\% gelatine (w/w). Both formulated emulsions have already used in a previous work, whose aim was to evaluate how microencapsulation conditions affected the physicochemical characteristics of microcapsules (Holgado et al., 2013). A coarse emulsion was first prepared in a DI-25 Ultraturrax (IKA, Germany) by applying $454 \boldsymbol{g}(8,000 \mathrm{rpm})$ for $2 \mathrm{~min}, 641 \boldsymbol{g}(9,500 \mathrm{rpm})$ for 2 min and $1294 \boldsymbol{g}(13,500 \mathrm{rpm})$ for 1 min. Then, the coarse emulsion was homogenised in an EmulsiFlex-C5 (Avestin Inc., Canada) high pressure homogeniser by applying 15 or $70 \mathrm{MPa}$ and one pass. Each emulsion was frozen at $-32{ }^{\circ} \mathrm{C}$ for $24 \mathrm{~h}$ and freeze-dried in a lab-scale Heto FD3 freeze-dryer (Allerød, 
Denmark) for $48 \mathrm{~h}$. Finally, the dried samples were ground in batches of $20 \mathrm{~g}$ in a domestic electronic coffee grinder of $400 \mathrm{~mL}$ volume for $10 \mathrm{~s}$ at interval of $5 \mathrm{~s}$.

\section{Physicochemical properties of the DMOs}

Microencapsulation efficiency (ME)

ME was determined according to a previous study (Holgado et al., 2013).

\section{Oil droplet size}

Analysis of oil droplet size was performed in reconstituted emulsions obtained by dispersing the DMO samples in water at a weight proportion of 1:7 according to Holgado et al. (2019). A Malvern Mastersizer X (Malvern Instruments, Malvern, UK) was also used at the same conditions as described elsewhere (Holgado et al., 2019). Ultrasound was applied in the sample dispersion unit to evaluate whether the changes observed were due to changes in the droplet size or to droplet flocculation. The application of ultrasound resulted in unchanged results in all the samples analysed, so flocculation was discarded. The effect of the drying method on the oil droplet size was studied in a previous work (Holgado et al., 2013).

\section{Water activity}

Water activity was measured with a PawKit hygrometer (DECAGON, USA).

\section{Glass transition temperature}

The glass transition temperature (Tg) was determined with a DSC Q2000 calorimeter (TA Instruments, New Castle, DE, USA) as described elsewhere (Holgado et al., 2013).

\section{Storage conditions}

DMO samples $(10 \mathrm{~g})$ were placed on Petri dishes and stored in desiccators at $30^{\circ} \mathrm{C}$ in the dark and $0.0 \%$ relative humidity (silica gel). Periodic samplings were performed in a period of 170 days. The samples were kept at $-25^{\circ} \mathrm{C}$ until analysis. 


\section{Oil extraction}

The free or non-encapsulated oil was extracted from $10 \mathrm{~g}$ of DMO, with $100 \mathrm{~mL}$-hexane and stirring for $15 \mathrm{~min}$ at room temperature, as previously reported (Holgado et al., 2013). After the extraction of the free oil from $10 \mathrm{~g}$ of DMO, the encapsulated oil was extracted by a procedure based upon a mortar and pestle detailed elsewhere (Holgado et al., 2019).

\section{Evaluation of oxidation}

The oxidation state of the oil extracts from initial DMO samples and the oil used in the DMO preparation was evaluated by a combination of solid-phase extraction (SPE) and highperformance size-exclusion chromatography (HPSEC) analysis, according to a previous report (Holgado et al., 2019). The total fraction of polar compounds and the individual groups that form it, i.e. triacylglycerol oligomers (TGO), triacylglycerol dimers (TGD), oxidised triacylglycerol monomers (oxTGM), diacylglycerols (DG) and free fatty acids (FFA), were determined quantitatively. In addition, the peroxide value (PV) and the content of tocopherol were also analysed.

The oxidised DMO samples were evaluated applying the PV, the levels of triacylglycerol polymers by HPSEC analysis and the loss of tocopherols, described in a previous report (Holgado et al., 2019).

\section{Statistical analysis}

Analyses were carried out in triplicate samples. One-factor ANOVA was applied using 24.0 SPSS Statistics program (SPSS Inc., Chicago, IL, USA). Tukey's test was used for multiple comparisons. Significance was defined at $p<0.05$. 


\section{Results and discussion}

\section{Physicochemical characteristics of the DMO samples}

The homogenisation conditions applied rendered samples with varying oil droplet size and different oil fraction distribution in the encapsulation matrix (Table 1). The ME was not high, but showed normal values for samples obtained by freeze-drying (Bakry et al., 2016). The reconstituted emulsions from CAS samples presented a unimodal size distribution, smaller values for the mean oil droplet size and droplets in a much narrower size range than the MD samples, whose reconstituted emulsions showed a bimodal distribution (not shown). However, the ME was higher for the MD samples even when the average surface area $\left(A_{N}\right)$ for the lipid fraction was far greater for the CAS samples, as previously reported (Holgado et $a l ., 2013)$. The homogenisation pressure exerted greater influence on the oil droplet size in the CAS sample, showing that its encapsulating matrix imparted a greater stabilizing effect on the lipid phase than the MD sample. As a result, the ME increased proportionally more in the CAS sample when the homogenisation pressure was increased.

The water activity of the samples was very low and similar for the two types of DMO, showing values that were around 0.05 . The Tg values were higher for the CAS samples, indicating a greater structural stability (Table 1). In fact, significant differences in the ME were not observed in the CAS samples along the oxidation assay, which indicates that the matrix did not undergo changes in its structure that gave rise to changes in the oil distribution. In contrast, a significant rise in the ME up to $95 \%$ occurred in the MD samples from $100 \mathrm{~d}$ of storage, as also found in a recent study (Holgado et al., 2019).

\section{Initial DMO samples}

Results for the initial oil and the oil extracts from the DMO samples are listed in Table 2. Very slight increases in the content of oxTGM and the PV were found in the DMO samples, indicating slight oxidation during sample preparation. Significant losses of tocopherols were 
also observed and these were significantly greater in the MD samples. The free oil in the MD samples was slightly more oxidised than the encapsulated oil, whereas this fact was not clear in the CAS samples. Regardless of the type of matrix, significant changes in the oxidative state of the encapsulated fraction were not observed when the homogenisation pressure was increased. In fact, the content of oxTGM and also the PV remained unchanged. However, the incipient oxidation of the free oil of the CAS sample was lower when the homogenisation pressure was increased. This fact was not clear in the MD sample as the oxTGM content did not show significant differences, but slightly higher PV was found in the MD70 sample.

\section{Oxidised DMO samples}

In the four samples studied, the free oil fraction presented an oxidative pattern characteristic of bulk oils, i.e. of a continuous phase, whereas oxidation in the encapsulated fraction occurred discontinuously, as reported in a previous study (Holgado et al., 2019). In this respect, the free oil showed a well-defined induction period after which complete depletion of tocopherols and onset of significant polymerization took place (Figure 1). On the other hand, significant levels of polymers were found in the encapsulated oil when the tocopherol content was still elevated, which was indicative of droplets with different oxidation states (Velasco et al., 2006; 2009a; Morales et al., 2015).

In the CAS samples, the PV increased similarly in the two oil fractions during the early stages of oxidation (Figure 1a). In addition, tocopherols were completely depleted at similar oxidation periods in both fractions (Figure 1c). Therefore, the encapsulation matrix did not seem to provide greater protection to the encapsulated fraction. From the results obtained by the three analytical determinations applied, it was evident that the CAS70 sample was more stable against oxidation than the CAS15 sample (Figure 1a-c).

In the MD samples, the PV increased more slowly in the encapsulated oil than in the free oil during the early stages of oxidation. This fact was more evident in the MD70 sample, 
although it was also observed in the MD15 sample when the PV was up to $200 \mathrm{meq} / \mathrm{kg}$ (Figure 1a'). Therefore, the MD matrix seemed to protect the encapsulated oil against oxidation. While the PV showed greater oxidative stability for the MD70 sample at the beginning of the assay, the increase of polymers and the losses of tocopherols indicated the opposite at the end (Figure 1b'-c'). In fact, the total loss of tocopherols and the onset of substantial polymerization in the free oil occurred before in the MD70 sample than in MD15. However, when the end of the induction period of any given oil is reached, the oxidation level is extremely high from the point of view of rancidity perception (Velasco et al., 2010). For practical purposes, it would be more appropriate to examine the oxidative development during the first stages of the process and not at the end of the induction period. According to a recent report (Holgado et al., 2019), oxidation extent up to levels of PV of $100 \mathrm{meq} / \mathrm{kg}$ has shown to be a good maximum limit to evaluate oxidation in DMOs.

Table 3 lists the periods at which the PV reached $100 \mathrm{meq} / \mathrm{kg}$ and also, for comparative purposes, those when tocopherols were exhausted. The PV exhibited similar or greater oxidative stability for the encapsulated oil fraction than for the free oil, showing the protective role of the two encapsulation matrices against the diffusion of oxygen. In addition, the PV during early oxidation also showed greater oxidative stability for the samples prepared with $70 \mathrm{MPa}$, i.e. for those with smaller oil droplet size, than those made with $15 \mathrm{MPa}$.

The greater oxidative stability of the samples containing smaller oil droplet sizes is in agreement with reported studies in which only the total oil fraction was analysed (Ishido et al., 2002; Minemoto et al., 2002; Nakazawa et al., 2008; Ramakrishnan et al., 2014; Abd Ghani et al., 2016; Shiga et al., 2017). The results of the present study showed that a significant reduction in the oil droplet size enhanced the oxidative stability of the encapsulated oil and also that of the free oil fraction (Table 3). Therefore, the improved oxidative stability of the DMOs can not only be attributed to a decrease of the surface oil 
content as it was concluded in previous studies (Ishido et al., 2002; Minemoto et al., 2002; Nakazawa et al., 2008; Ramakrishnan et al., 2014; Abd Ghani et al., 2016; Shiga et al., 2017). According to Drusch and Berg (2008), the free oil fraction is mainly constituted by the surface oil, formed by discrete oil deposits that are not stabilised by an interfacial layer and are localized on the particle surface, porous and capillaries. In addition, inner droplets close to the particle surface that are accessible to the organic solvent also contribute to this fraction. It is highly likely that these droplets were completely covered and protected by the wall and that they were accessible to the organic solvent when the surface oil was first removed during the oil extraction. This inner oil sub-fraction would have to constitute an important part of the free oil to explain the increase in stability observed when the droplet size was reduced. Conversely, studies on fat localisation have shown by applying different approaches that the surface oil is by far the main part of the extractable oil (Gejl-Hansen \& Flink, 1977; Drusch \& Berg, 2008; Foerster et al., 2016).

Foerster et al. (2016) observed that the free oil constituted a continuous film that covered the powder particles in a dried emulsion model containing similar composition to the CAS samples of the present work. This would be consistent with the fact that the free oil oxidised like a continuous lipid phase. However, if the free fraction had also been formed by individual droplets, its oxidation would have proceeded discontinuously in a similar way to the encapsulated fraction. Although the onset of substantial polymerization when tocopherol is completely lost is characteristic of the oxidation of oils in continuous phase, an uneven loss of the antioxidant could be due to oil droplets or oil sub-fractions oxidising at different rates. That was the case of the free oil in the MD samples (Figure 1c'), but it was not observed in the CAS samples. In addition, the levels of polymers accumulated during the induction period were different between samples prepared with different homogenisation pressure regardless of the type of matrix (Figure 1b-b'). This fact could also be indicative of oil droplets with 
different oxidation states, i.e. droplets with low oxidation and droplets within advanced oxidation containing substantial polymerisation compounds. Therefore, the results seem to indicate that part of the free oil fraction also oxidised discontinuously.

Not less interesting was the fact that the oxidative stability of the microencapsulated oil also increased when the oil droplet size was reduced. An increase in oxidative stability as a result of a reduction in the surface oil content would only apply to the free oil, but obviously not to the encapsulated fraction. The interfacial layer of the oil droplets, often neglected, may play a very significant role in creating an additional oxygen barrier. The oil-matrix interface has a composition different from the bulk encapsulation matrix and thus may be a more or less effective barrier to oxygen diffusion than the bulk wall material (Reineccius \& Yan, 2016). If the interfacial film were effective by providing additional protection, a significant increase in the oxidative stability of the encapsulated oil could be explained by a decrease in the oil droplet size. Similarly, the droplets that contribute to the free oil fraction and preserve their interfacial layer would also be more stable against lipid oxidation with a decrease in their particle size and would also contribute to the increased oxidative stability observed in the free oil fraction.

\section{Conclusions}

A reduction of the oil droplet size by applying greater homogenisation pressure in the emulsification step gave rise to increased oxidative stability of the free and encapsulated oil fractions in two matrices of different chemical nature. Therefore, the increase in oxidative stability was not only due to a reduction of the surface oil content as concluded in most studies in which only the total oil fraction was evaluated. This would only apply to the free oil fraction, but not to the encapsulated oil. Results suggested that the free fraction of freezedried microencapsulated oil was also formed by droplets that maintained their interfacial layer and were protected by the solid matrix. The interfacial layer may have provided additional 
protection to the droplets of the encapsulated oil. In conclusion, if the encapsulation matrix and the interfacial film are effective as oxygen barriers, a reduction of the oil droplet size of the parent emulsion by an increase in the homogenisation pressure will result in capsules more stable against lipid oxidation.

\section{Acknowledgements}

This work was funded by the Spanish Ministry of Economy, Industry and Competitiveness through project AGL2013-45110-R.

\section{Data availability}

The data that support the findings of this study are available from the corresponding author upon reasonable request.

\section{Ethical guidelines}

Ethics approval was not required for this research.

\section{Conflict of interest}

The authors declare that there are no conflicts of interest regarding the research, authorship or publication of this article. 


\section{References}

Anwar, S.H. \& Kunz, B. (2011). The influence of drying methods on the stabilization of fish oil microcapsules: Comparison of spray granulation, spray drying, and freeze drying. Journal of Food Engineering, 105, 367-378.

Abd Ghani, A., Matsumura, K., Yamauchi, A., Shiga, H., Adachi, S., Izumi, H. \& Yoshii, H. (2016). Effects of oil-droplet diameter on the stability of squalene oil in spray-dried powder. Drying Technology, 34, 1726-1734.

Bakry, A. M., Abbas, S., Ali, B., Majeed, H., Abouelwafa, M. Y., Mousa, A. \& Liang, L. (2016). Microencapsulation of Oils: A Comprehensive Review of Benefits, Techniques, and Applications. Comprehensive Reviews in Food Science and Food Safety, 15, 143-182.

Drusch, S. \& Berg, S. (2008). Extractable oil in microcapsules prepared by spray-drying: Localisation, determination and impact on oxidative stability. Food Chemistry, 109, $17-$ 24.

Drusch, S., Serfert, Y., Scampicchio, M., Schmidt-Hansberg, B. \& Schwarz, K. (2007). Impact on physicochemical characteristics on the oxidative stability of fish oil microencapsulated by spray-drying. Journal of Agricultural and Food Chemistry, 55, 11044-11051.

Foerster, M., Gengenbach, T., Woo, M. W. \& Selomulya, C. (2016). The influence of the chemical surface composition on the drying process of milk droplets. Advanced Powder Technology, 27, 2324-2334.

Gejl-Hansen, F. \& Flink, J. M. (1977) Freeze-dried carbohydrate containing oil-in-water emulsions: microstructure and fat distribution. Journal of Food Science, 42, 1049-1055.

Ghnimi, S., Budilarto, E. \& Kamal-Eldin, A. (2017). The New Paradigm for Lipid Oxidation and Insights to Microencapsulation of Omega-3 Fatty Acids. Comprehensive Reviews in Food Science and Food Safety, 16, 1206-1218. 
Hogan, S. A., McNamee, B. F., O’Riordan, E. D. \& O’Sullivan, M. (2001). Emulsification and microencapsulation properties of sodium caseinate/carbohydrate blends. International Dairy Journal, 11, 137-144.

Holgado, F., Márquez-Ruiz, G., Dobarganes, C. \& Velasco, J. (2013). Influence of homogenisation conditions and drying method on physicochemical properties of dehydrated emulsions containing different solid components. International Journal of Food Science and Technology, 48, 1498-1508.

Holgado, F., Márquez-Ruiz, G., Ruiz-Méndez, M. V. \& Velasco, J. (2019). Effects of the drying method on the oxidative stability of the free and encapsulated fractions of microencapsulated sunflower oil. International Journal of Food Science and Technology, 54, 2520-2528.

Ishido, E., Hakamata, K., Minemoto, Y., Adachi, S. \& Matsuno, R. (2002). Oxidation process of linoleic and encapsulated with a polysaccharide by spray-drying. Food Science and Technology Research, 8, 85-88.

Ixtaina, V. Y., Julio, L. M., Wagner, J. R., Nolasco, S. M. \& Tomas, M. C. (2015). Physicochemical characterization and stability of chia oil microencapsulated with sodium caseinate and lactose by spray-drying. Powder Technology, 271, 26-34.

Jafari, S. M., Assadpoor, E., Bhandari, B. \& He, Y. (2008). Nano-particle encapsulation of fish oil by spray drying. Food Research International, 41, 172-183.

Keogh, M. K., O'Kennedy, B. T., Kelly, J., Auty, M. A., Kelly, P. M., Fureby, A. \& Haahr, A.-M. (2001). Stability to oxidation of spray-dried fish oil powder microencapsulated using milk ingredients. Journal of Food Science, 66, 217-224.

Márquez-Ruiz, G., Velasco, J. \& Dobarganes, C. (2003). Oxidation in dried microencapsulated oils. In: Lipid Oxidation Pathways (edited by A. Kamal-Eldin). Pp. 245-264. Champaign, USA: AOCS Press.

Minemoto, Y., Hakamata, K., Adachi, S. \& Matsuno, R. (2002). Oxidation of linoleic acid encapsulated with gum arabic or maltodextrin by spray-drying. Journal of Microencapsulation, 19, 181-189. 
Morales, A., Marmesat, S., Ruiz-Mendez, M. V., Marquez-Ruiz, G. \& Velasco, J. (2015). New analytical evidence of discontinuous oxidation in dried microencapsulated lipids. Journal of the American Oil Chemists Society, 92, 1601-1607.

Nakazawa, R., Shima, M. \& Adachi, S. (2008). Effect of Oil-droplet Size on the Oxidation of Microencapsulated Methyl Linoleate. Journal of Oleo Science, 57, 225-232.

Ramakrishnan, S., Ferrando, M., Aceña-Muñoz, L., Mestres, M., De Lamo-Castellví, S. \& Güell, C. (2014). Influence of emulsification technique and wall composition of physicochemical properties and oxidative stability of fish oil microcapsules produced by spray drying. Food and Bioprocess Technology, 7, 1959-1972.

Reineccius, G. A. \& Yan, C. (2016). Factors controlling the deterioration of spray dried flavourings and unsaturated lipids. Flavour and Fragrance Journal, 31, 5-21.

Risch, S. J. \& Reineccius, G. A. (1988). Spray-dried orange oil. Effect of emulsion size on flavor retention and shelf stability. In: Flavor Encapsulation (edited by S. J. Risch \& G. A. Reineccius). Pp. 67-77. Washinton D.C.: American Chemical Society.

Ruiz-Ruiz, J. C., Ortiz-Vazquez, E. L. \& Segura-Campos, M. R. (2017). Encapsulation of vegetable oils as source of omega-3 fatty acids for enriched functional foods. Critical Reviews in Food Science and Nutrition, 57, 1423-1434.

Rusli, J. K., Sanguansri, L. \& Augustin, M. A. (2006). Stabilization of oils by microencapsulation with heated protein-glucose syrup mixtures. Journal of the American Oil Chemists' Society, 83, 965-972.

Shiga, H., Neoh, T. L., Ninomiya, A., Adachi, S., Pasten, I. L. \& Yoshii, H. (2017). Effect of oil droplet size on the oxidative stability of spray-dried flaxseed oil powders. Bioscience Biotechnology and Biochemistry, 81, 698-704.

Soottitantawat, A., Bigeard, F., Yoshii, H., Furuta, T., Ohkawara, M. \& Linko, P. (2005). Influence of emulsion and powder size on the stability of encapsulated D-limonene by spray drying. Innovative Food Science \& Emerging Technologies, 6, 107-114.

Soottitantawat, A., Yoshii, H., Furuta, T., Ohkawara, M. \& Linko, P. (2003). Microencapsulation by spray drying: Influence of emulsion size on the retention of volatile compounds. Journal of Food Science, 68, 2256-2262. 
Velasco, J., Dobarganes, C., Holgado, F. \& Márquez-Ruiz, G. (2009b). A follow-up oxidation study in dried microencapsulated oils under the accelerated conditions of the Rancimat test. Food Research International, 42, 56-62.

Velasco, J., Dobarganes, C. \& Márquez-Ruiz, G. (2010). Oxidative rancidity in foods and food quality. In: Chemical Deterioration and Physical Instability of Foods and Beverages (edited by L. Skibsted, J. Risbo and M. Andersen). Pp. 3-32. Cambridge, UK: Woodhead Publishing Limited.

Velasco, J., Holgado, F., Dobarganes, C. \& Márquez-Ruiz, G. (2009a). Influence of relative humidity on oxidation of the free and encapsulated oil fractions in freeze-dried microencapsulated oils. Food Research International, 42, 1492-1500.

Velasco, J., Marmesat, S., Dobarganes, C. \& Márquez-Ruiz, G. (2006). Heterogeneous aspects of lipid oxidation in dried microencapsulated oils. Journal of Agricultural and Food Chemistry, 54, 1722-1729. 


\section{Figure legends}

Figure 1 Oxidation of the free (FRE) and encapsulated (ENC) oil fractions in the CAS (a-c) and MD (a'-c') samples obtained from emulsions prepared with 15 or $70 \mathrm{MPa}$. The samples were oxidised at $30{ }^{\circ} \mathrm{C}$ in the dark and $0.0 \% \mathrm{RH}$. Data correspond to mean values and the error bars show the standard deviation $(n=3)$. 
(a)

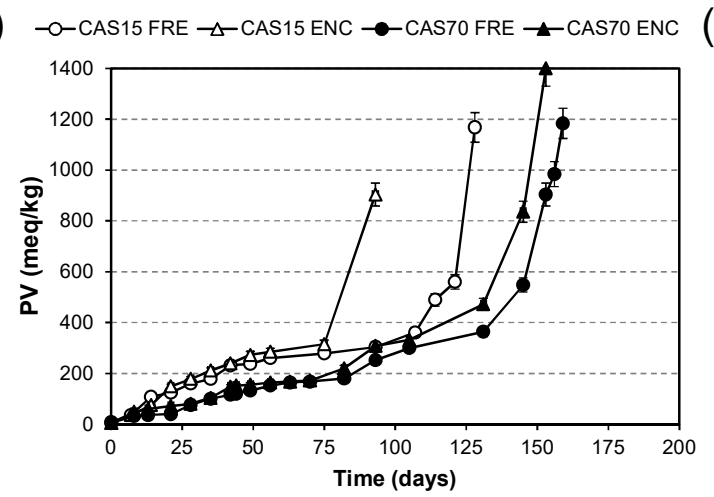

(b)

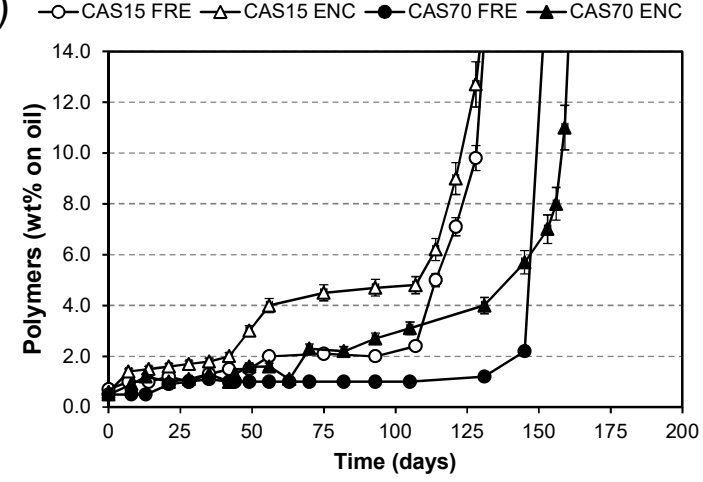

(c) - O-CAS15 FRE $\triangle-$ - CAS15 ENC $\rightarrow$ - CAS70 FRE $₫$ CAS70 ENC

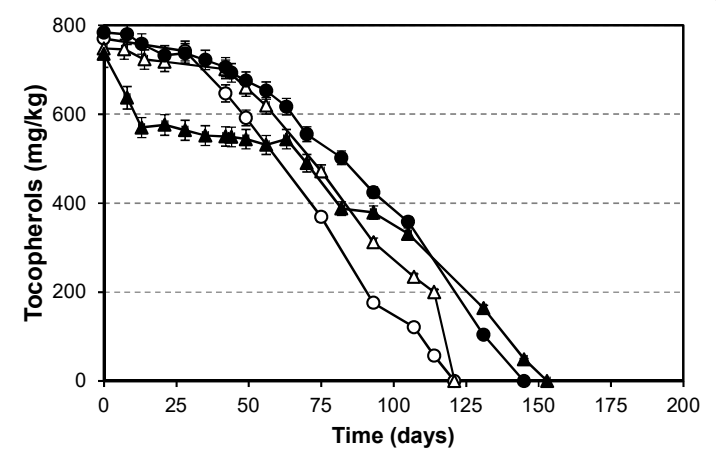

(a') -O-MD15 FRE $\triangle-M D 15$ ENC - -MD70 FRE $\neg-$ MD70 ENC

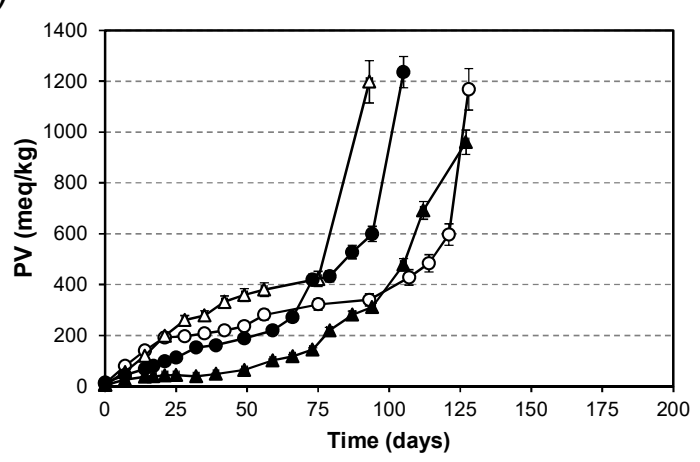

(b') -O-MD15 FRE $\triangle-$ MD15ENC $\rightarrow-M D 70$ FRE $₫$ MD70 ENC

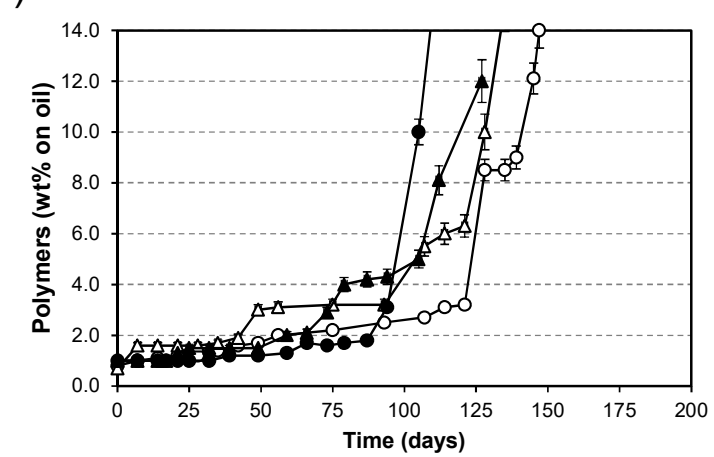

(c') -O-MD15FRE $\triangle$-MD15 ENC $\rightarrow$-MD70FRE $\_$MD70 ENC

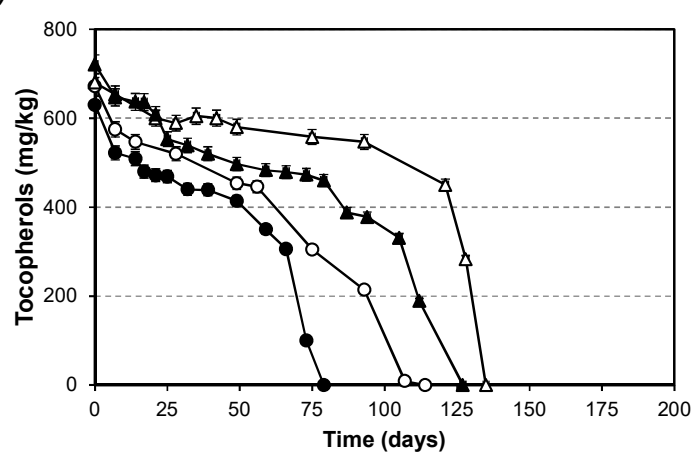

Figure 1 
Table 1 Physicochemical characteristics of the dried microencapsulated oil samples.

\begin{tabular}{lllll}
\hline & CAS15 & CAS70 & MD15 & MD70 \\
\hline ME $(\%)$ & $48.1 \pm 2.9 \mathrm{a}$ & $61.2 \pm 1.1 \mathrm{~b}$ & $65.7 \pm 3.8 \mathrm{~b}$ & $77.1 \pm 2.3 \mathrm{c}$ \\
Oil droplet size: & & & & \\
$\mathrm{d}_{(\mathrm{v}, 0.5)}(\mu \mathrm{m})$ & $1.29 \pm 0.15 \mathrm{~b}$ & $0.85 \pm 0.02 \mathrm{a}$ & $4.23 \pm 0.01 \mathrm{c}$ & $3.77 \pm 0.04 \mathrm{~d}$ \\
$\mathrm{~d}_{(\mathrm{v}, 0.9)-\mathrm{d}_{(\mathrm{v}, 0.1)}(\mu \mathrm{m})}$ & $5.54 \pm 0.04 \mathrm{~b}$ & $3.47 \pm 0.06 \mathrm{a}$ & $19.41 \pm 0.26 \mathrm{c}$ & $20.50 \pm 0.82 \mathrm{c}$ \\
$\mathrm{d}_{32}(\mu \mathrm{m})$ & $0.90 \pm 0.03 \mathrm{~b}$ & $0.55 \pm 0.04 \mathrm{a}$ & $1.85 \pm 0.01 \mathrm{~d}$ & $1.48 \pm 0.02 \mathrm{c}$ \\
$\mathrm{A}_{\mathrm{N}}\left(\mu \mathrm{m}^{-1}\right)$ & $6.67 \pm 0.22 \mathrm{c}$ & $10.95 \pm 0.80 \mathrm{~d}$ & $3.24 \pm 0.02 \mathrm{~b}$ & $4.05 \pm 0.05 \mathrm{a}$ \\
& & & & $0.04 \pm 0.00 \mathrm{a}$ \\
Water activity & $0.04 \pm 0.00 \mathrm{a}$ & $0.06 \pm 0.00 \mathrm{~b}$ & $0.08 \pm 0.01 \mathrm{c}$ & $0.04 \pm 0.4 \mathrm{a}$ \\
\hline
\end{tabular}

CAS, samples prepared with sodium caseinate and lactose; MD, samples containing maltodextrin, sucrose and gelatine; the number after the sample name means the homogenisation pressure applied in the emulsification step; ME, microencapsulation efficiency; $d_{(v, 0.5)}$, mean droplet size; $d_{(v, 0.9)}-d_{(v, 0.1)}$, range of droplet sizes; $d_{32}$, Sauter mean diameter; $\mathrm{A}_{\mathrm{N}}$, average surface area. Results are expressed as mean \pm standard deviation $(\mathrm{n}=3)$. Different letters for each determination denote significance differences $(P<0.05)$. 
Table 2 Characterisation of the initial oil and the oils extracted from the initial dried microencapsulated oil samples.

\begin{tabular}{|c|c|c|c|c|c|c|c|}
\hline \multirow{2}{*}{ Sample } & \multirow{2}{*}{$\begin{array}{l}\text { TPC } \\
\text { (wt\% on oil) }\end{array}$} & \multicolumn{4}{|c|}{ PC distribution (wt\% on oil) } & \multirow{2}{*}{$\begin{array}{l}\mathrm{PV} \\
(\mathrm{meq} \mathrm{O} / \mathrm{kg})\end{array}$} & \multirow{2}{*}{$\begin{array}{l}\text { Toc } \\
(\mathrm{mg} / \mathrm{kg})\end{array}$} \\
\hline & & TGO+TGD & oxTGM & DAG & FFA* & & \\
\hline Oil & $4.9 \pm 0.1 \mathrm{a}$ & $0.7 \pm 0.1 \mathrm{ab}$ & $2.4 \pm 0.1 \mathrm{a}$ & $1.4 \pm 0.1 \mathrm{ab}$ & $0.4 \pm 0.0 \mathrm{a}$ & $3.0 \pm 0.1 \mathrm{a}$ & $891 \pm 12 \mathrm{f}$ \\
\hline CAS15 FRE & $5.6 \pm 0.1 \mathrm{~b}$ & $0.7 \pm 0.1 \mathrm{ab}$ & $2.9 \pm 0.2 \mathrm{bc}$ & $1.5 \pm 0.1 \mathrm{ab}$ & $0.5 \pm 0.0 \mathrm{ab}$ & $8.1 \pm 0.4 \mathrm{~d}$ & $780 \pm 22 \mathrm{e}$ \\
\hline CAS15 ENC & $5.4 \pm 0.1 \mathrm{~b}$ & $0.6 \pm 0.1 \mathrm{ab}$ & $2.5 \pm 0.1 \mathrm{ab}$ & $1.5 \pm 0.1 \mathrm{ab}$ & $0.8 \pm 0.0 \mathrm{~d}$ & $5.5 \pm 0.3 \mathrm{bc}$ & $745 \pm 20 \mathrm{de}$ \\
\hline CAS70 FRE & $4.9 \pm 0.1 \mathrm{a}$ & $0.5 \pm 0.1 \mathrm{a}$ & $2.3 \pm 0.1 \mathrm{a}$ & $1.5 \pm 0.1 \mathrm{ab}$ & $0.6 \pm 0.0 \mathrm{bc}$ & $4.3 \pm 0.3 \mathrm{ab}$ & $780 \pm 18 \mathrm{e}$ \\
\hline CAS70 ENC & $4.9 \pm 0.1 \mathrm{a}$ & $0.5 \pm 0.1 \mathrm{a}$ & $2.4 \pm 0.1 \mathrm{a}$ & $1.4 \pm 0.1 \mathrm{ab}$ & $0.7 \pm 0.0 \mathrm{~cd}$ & $5.1 \pm 0.2 \mathrm{bc}$ & $737 \pm 22$ cde \\
\hline MD15 FRE & $5.9 \pm 0.1 \mathrm{c}$ & $0.8 \pm 0.1 \mathrm{~b}$ & $3.2 \pm 0.2 \mathrm{c}$ & $1.4 \pm 0.1 \mathrm{ab}$ & $0.5 \pm 0.1 \mathrm{ab}$ & $10.6 \pm 0.6 \mathrm{e}$ & $668 \pm 15 \mathrm{ab}$ \\
\hline MD15 ENC & $5.5 \pm 0.1 \mathrm{~b}$ & $0.7 \pm 0.1 \mathrm{ab}$ & $2.6 \pm 0.1 \mathrm{ab}$ & $1.6 \pm 0.1 \mathrm{~b}$ & $0.6 \pm 0.0 \mathrm{bc}$ & $5.8 \pm 0.7 \mathrm{c}$ & $686 \pm 20 \mathrm{bc}$ \\
\hline MD70 FRE & $5.4 \pm 0.1 \mathrm{~b}$ & $0.7 \pm 0.0 \mathrm{ab}$ & $2.9 \pm 0.1 \mathrm{bc}$ & $1.4 \pm 0.1 \mathrm{ab}$ & $0.4 \pm 0.1 \mathrm{a}$ & $13.6 \pm 0.7 \mathrm{f}$ & $631 \pm 18 \mathrm{a}$ \\
\hline MD70 ENC & $4.9 \pm 0.1 \mathrm{a}$ & $0.8 \pm 0.1 \mathrm{~b}$ & $2.3 \pm 0.2 \mathrm{a}$ & $1.3 \pm 0.1 \mathrm{a}$ & $0.5 \pm 0.0 \mathrm{ab}$ & $5.2 \pm 0.6 \mathrm{bc}$ & $725 \pm 22 \mathrm{~cd}$ \\
\hline
\end{tabular}

FRE, free oil fraction; ENC, encapsulated oil fraction; TPC, total polar compounds; TGO, triacylglycerol oligomers; TGD, triacylglycerol dimers; oxTGM, oxidised triacylglycerol monomers; DAG, diacylglycerols, FFA*, free fatty acids and other polar minor oil components; PV, peroxide value; Toc, tocopherols. Results are expressed as mean \pm standard deviation $(\mathrm{n}=3)$. Different letters for each determination denote significance differences $(P<0.05)$. 
Table 3 Oxidation time periods at which tocopherols were completely depleted and when the PV reached 100 meq $\mathrm{kg}^{-1}$ oil.

\begin{tabular}{llllll}
\hline \multirow{2}{*}{ Sample } & \multicolumn{2}{l}{ Time $_{\mathbf{T o c}=\mathbf{0}}(\mathbf{d})$} & & \multicolumn{2}{l}{ Time $\mathbf{P V = 1 0 0}(\mathbf{d})$} \\
\cline { 2 - 3 } \cline { 5 - 6 } & Free & Encapsulated & & Free & Encapsulated \\
\hline CAS15 & $114-121$ & $114-121$ & & $7-14$ & $14-21$ \\
CAS70 & $131-145$ & $145-153$ & & 35 & 35 \\
MD15 & $107-114$ & $128-135$ & & $7-14$ & $7-14$ \\
MD70 & $73-79$ & $112-127$ & 21 & 59 \\
\hline
\end{tabular}

